\title{
Ovarian Non-Hodgkin's Lymphoma from a Regional Cancer Centre in South India
}

\author{
Suresh Babu11 , Usha Amirtham², Lokesh K.N1, Govind \\ Babu.K1', Lakshmaiah K.C'1, Lokanatha Dasappa' ${ }^{1}$ C.S. \\ Premalata ${ }^{2}$, Linu Abraham Jacob ${ }^{1}$, Rudresh AH ${ }^{1}$, Rajeev LK', \\ Venugopal Arroju' 1
}

\author{
${ }^{1}$ Department and institution: Department of Medical Oncology, Kidwai Memorial Institute of Oncology, \\ Bangalore, Karnataka, India \\ ${ }^{2}$ Department of Pathology, Kidwai Memorial Institute of Oncology, Bangalore, India
}

\begin{abstract}
Primary Non-Hodgkin's Lymphoma of Ovary is a rare cancer. There is limited data in Indian population. Hence we undertook this retrospective observational study at our center in Southern India. This study includes 5 consecutive cases diagnosed as Primary Non-Hodgkin's Lymphoma of Ovary between January 2009 and December 2015. Primary Non-Hodgkin's lymphoma (NHL) of the ovary is rare with an incidence in the literature of $0.5 \%$ of NHL and $1.5 \%$ of ovarian tumours. Diffuse large B-cell type accounts for about $20 \%$ of PONHL. We studied five cases of primary ovarian NHL. All cases were diffuse large B-cell lymphoma of ovary. The patients ranged in age from 41 years to 59 years with median age of presentation 50 years. Pain abdomen was the most common symptom (3/5-60\%). According to Ann Arbor stage- Advanced stage ( IVE) was seen in 3 patients ( $60 \%)$ and the rest 2 patients $(40 \%)$ had stage IE. 4 patients had Eastern co-operative oncology group (ECOG) performance status -1 and 1 patient had ECOG PS -2 . B symptoms were seen in 3 out of 5 patients $(60 \%)$. According to IPI, 3 patients $(60 \%)$ were in low intermediate risk and 2 patients (40\%) had low risk score. 1 case was positive for BCL-6, 1 case was positive for CD10, 3 cases were positive for BCL-2, and 4 cases were positive for CD 20 . Patients were treated by various combinations of surgery, chemotherapy, and radiotherapy. Overall survival ranged from 6 months to 41 months with median OS of 23 months.
\end{abstract}

\section{Introduction}

Involvement of the ovary by malignant lymphoma, particularly Non-Hodgkin's lymphoma (NHL) is a well-known manifestation of disseminated lymphoma with a frequency of $7 \%$ to 26\% [1]. However, presumably Primary Ovarian Non-Hodgkin's lymphoma (PONHL) is rare and accounts for $0.5 \%$ of $\mathrm{NHL}$ and $1.5 \%$ of ovarian tumours. Diffuse large B-cell type accounts for about $20 \%$ of PONHL. All of the cases presented in this report were diffuse large B-cell lymphoma. Primary ovarian lymphoma may be misdiagnosed as epithelial ovarian malignancy. This study describes 5 cases of ovarian NHL.

Materials and Methods

This was a retrospective observational study done at Kidwai Memorial Institute of Oncology, Bengaluru, a tertiary care centre in Southern India. All consecutive cases, diagnosed as Ovarian Non-
Hodgkin's Lymphoma between January 2009 and December 2015 were enrolled. An informed consent was taken from all the patients and demographic details, clinical details, investigations and treatment details were recorded and analysed. Evaluation included history, physical examination, complete hemogram, Serum Biochemistry, HIV, HBS-Ag and Echocardiography. Computed tomography (CT) scans of Neck, Thorax, Abdomen, Pelvis was done for all the patients. Bone marrow biopsy from iliac crest was done in all the cases. Immuno histochemical studies were performed using formalin-fixed, paraffin-embedded tissue sections and a variable panel of antibodies specific for the following antigens: CD3, CD20, CD21, CD30, CD99, BCL-2, BCL-6, and CD10, CD43and TdT.

This article is published under the terms of the Creative Commons Attribution License 4.0 Author(s) retain the copyright of this article. Publication rights with Alkhaer Publications. Published at: http://www.ijsciences.com/pub/issue/2016-05/ DOI: 10.18483/ijSci.1011; Online ISSN: 2305-3925; Print ISSN: 2410-4477 
Patients were staged according to Ann-Arbor staging as modified by Cotswold's and International Prognostic Scoring (IPI) was done. Each neoplasm was classified according to the World Health Organization Classification. 2 patients presented with stage I disease and 3 patients presented with stage IV disease. All patients underwent Total abdominal Hysterectomy and Bilateral Sapling- oophorectomy. Histopathological Diagnosis of DLBCL was made after surgery .They received either combination of R-CHOP (rituximab $375 \mathrm{mg} / \mathrm{m}^{2}$, cyclophosphamide $\quad 750 \mathrm{mg} / \mathrm{m}^{2}$, Adriamycin $50 \mathrm{mg} / \mathrm{m}^{2}$, vincristine $1.4 \mathrm{mg} / \mathrm{m}^{2}$ and prednisolone $100 \mathrm{mg} / \mathrm{d}$ for 5 days) 6 cycles or CHOP 6 cycles . Radiotherapy was given in 1 patient at a dose of $45 \mathrm{~Gy}$ in 25 \# for the patient who had Partial Response after R-CHOP. The responses were assessed according to standard criteria

Among these five patients one patient had relapsed disease after 18 months and received IMVP-16 regimen 6 cycles (Ifosfamide, Mesna, Etoposide).

Definitions: Foxet al. Proposed the following criteria for the diagnosis of PONHL.

1. At the time of diagnosis, the lymphoma is clinically confined to the ovary and a complete investigation fails to reveal evidence of lymphoma elsewhere. However, an ovarian lymphoma can still be considered as primary if it has spread to immediately adjacent lymph nodes or if it has directly spread to infiltrate immediately adjacent structures.

2. The peripheral blood and bone marrow should not contain any abnormal cells.

3. If further lymphomatous lesions occur at sites remote from the ovary, then at least

Several months should have elapsed between the appearance of the ovarian and extra ovarian lesions.

\section{Statistical Analysis}

Median survival was calculated using Microsoft excel, and overall survival was calculated from diagnosis to the last follow up or death due to any cause.

Results: A total of 5 patients with Primary Ovarian Non-Hodgkin's Lymphoma were included in the Study (Table 1). Median age was 50 years (41 to 59 years). 4 patients had Eastern cooperative oncology group (ECOG) performance status - 1. 1 patient had ECOG PS -2 . Pain abdomen was the most common symptom (3/5$60 \%$ ). B symptoms were seen in 3 patients $(60 \%)$. Each tumour was classified according to the World Health Organization Classification. All cases were of diffuse large B-cell lymphoma and no other histology was seen. According to Ann Arbor stage Advanced stage (stage IVE) was seen in 3 patients $(60 \%)$ and the rest 2 patients $(40 \%)$ had stage IE disease. According to IPI, 3 patients $(60 \%)$ were in low intermediate risk and 2 patients (40\%) had low risk score. BCL-6 was positive in 1 case, $\mathrm{CD} 10$ was positive in 1 case, BCL-2 was positive in 3 cases and CD 20 was positive in 4 cases. Patients were treated by various combinations of surgery, chemotherapy, and radiotherapy.

All patients underwent Total abdominal Hysterectomy and Bilateral Saplingoophorectomy. 1 patient received combination of R-CHOP (rituximab $375 \mathrm{mg} / \mathrm{m}^{2}$, cyclophosphamide $750 \mathrm{mg} / \mathrm{m}^{2}$, Adriamycin $50 \mathrm{mg} / \mathrm{m}^{2}$, vincristine $1.4 \mathrm{mg} / \mathrm{m}^{2}$ and prednisolone $100 \mathrm{mg} / \mathrm{d}$ for 5 days, 6 cycles) and 4 patients received CHOP, 6 cycles. Radiotherapy was given in 1 patient at a dose of 45 Gy in 25 \#. The responses were assessed according to standard criteria. Among these five patients one patient had relapsed disease after 18 months and received IMVP-16(Ifosfamide, Mesna, Etoposide) regimen for 6 cycles. Overall survival ranged from 6 months to 41 months with median OS of 23 months.

\section{Discussion:}

NHL uncommonly involves the gynecologic tract. However, when involved by NHL, the ovary is one of the more common anatomic sites. Previous studies of NHL involving gynecologic sites (1-3) have shown that most NHL involving the ovary are systemic tumors, of which ovarian involvement is only one aspect. Less than $10 \%$ of all ovarian NHLs reported have been localized, presumably arising in the ovary. In the current study, we collected five ovarian NHL, which have arisen in the ovary.

In normal ovaries, lymphocytes of B-cell and T-cell lineage are present within cortical granulomas, and rare lymphocytes are dispersed throughout the ovarian stroma and within ovarian follicles and corpora lutea (4). There is a possibility that chronic inflammation involving the ovaries predisposes to the development of NHL, analogous to low-grade B-cell MALT-lymphoma involving the stomach (5). Lymphomas of the ovary can occur at any age, but most often in women over the age of 40 with mean, 47 years age in 8 presented cases in one series) [5]. Our patients ranged in age from 41 to 59 years with median age 50 years. 4 patients had Eastern co-operative oncology group (ECOG) performance status - 1. 1 patient had ECOG PS -2. Lymphoma of the ovary may have varied presentations such as abdominal pain, pelvic mass, 
and ascites, fever, night sweats, fatigue, or weight loss (B symptoms). Patients may sought medical attention for pelvic complaints. In our study, Pain abdomen was the most common symptom (3/5$60 \%)$. 2 of 5 cases $(40 \%)$ presented with an abdominal mass. B symptoms were seen in 3 out of 5 patients $(60 \%)$. [6, 7].

In our study no patient was discovered as an incidental finding. However, it is noteworthy a subset of patients ovarian NHL was detected incidentally in a study by Russell Vang, M.D et al . The incidental neoplasms may arise in unusual settings, such as within the wall of an ovarian endometriotic cyst, or associated with a mature cystic teratoma or serous borderline tumor. In our study all tumours were unilateral. Bilaterality is infrequently seen. It is difficult to determine whether ovarian lymphomas are primary or secondary.

Fox et al. proposed the criteria for the diagnosis of PONHL [8]. Diffuse large B-cell lymphoma is the most common subtype of NHL and appears to be the most common type of primary ovarian NHL [9]. All cases in our study had diffuse large B-cell lymphoma. According to Ann Arbor stageAdvanced stage ( IVE) was seen in 3 patients ( 60 $\%$ ) and the rest $2(40 \%)$ had stage IE. According to IPI, 3 patients $(60 \%)$ were in low intermediate risk and 2 patients (40\%) had low risk score.

In our study 1 case of diffuse large B-cell lymphomas was positive for BCL-6, 1 was positive for $\mathrm{CD} 10$, and 3 cases were positive for BCL-2, 4 cases were positive for CD 20 . In other studies other histologies were also seen. In a series of eight cases by Russell Vang, M.D. et al three tumors were diffuse large B-cell lymphoma (DLBCL) and all three DLBCL were positive for CD20 and BCL-6, two cases were positive for CD10, and two cases were positive for BCL-2. Two cases were follicular lymphomas. Both cases were positive for CD10, CD20, and BCL-6 and negative for BCL-2. One case each was classified as Burkitt lymphoma, T-cell anaplastic large cell lymphoma (ALCL), and T-precursor lymphoblastic lymphoma (T-LBL) . Burkitt lymphoma was

Primary ovarian lymphoma have a poor outcome with a range from $0 \%$ to $36 \%$ expected to survive for less than three years [13]. Follow-up is relatively short in our series, as well as for those from the literature. Longer follow-up is needed to determine the long-term outcome.

\section{References}

1) Vang R, Medeiros LJ, Fuller GN, Sarris AH, Deavers M. Non-Hodgkin's lymphoma involving the gynecologic tract. A review of 88 cases. Adv Anat Pathol 2001;8:20017. positive for CD20 and BCL-6 but negative for CD10. The T-cell ALCL was positive for CD43 and CD30, but was negative for ALK-1. The TLBL was positive for CD3, CD10, CD99, and $\mathrm{TdT}$ and were negative for BCL-6.

Histologically similar neoplasms that should be differentiated from NHL involving the ovary include Adult granulosa cell tumor, dysgerminoma, and granulocytic sarcoma, poorly differentiated surface-epithelial or metastatic carcinomas, undifferentiated carcinoma, primitive neuroectodermal tumor (PNET), malignant mesodermal mixed tumour, endometrioid stromal sarcoma, desmoplastic small round cell tumor, poorly-differentiated Sertoli-Leydig cell tumor. Primary ovarian Lymphoma can mimic more frequently occurring tumors including advanced epithelial ovarian malignancy and, therefore, the correct diagnosis and optimal treatment would be missed without histopathological examination [10]. These patients may undergo radical surgery with the presumed diagnosis of an epithelial ovarian malignancy, whereas right diagnosis could allow optimal treatment, which is Chemotherapy, instead of radical surgery.

Patients were treated by various combinations of surgery, chemotherapy, and radiotherapy. All patients underwent Total abdominal Hysterectomy and Bilateral Salpingo- oophorectomy. They all received either combination of $\mathrm{R}-\mathrm{CHOP}$ or $\mathrm{CHOP}$. Radiotherapy was given in 1 patient at a dose of $45 \mathrm{~Gy}$ in $25 \#$ for Residual disease. One patient who received R- CHOP had Partial Response, 4 patients have received CHOP. Patient with PR had received Radiation. One patient had relapse after 18 months and received IMVP-16 regimen.

The protocol for chemotherapy used in diffuse large B-cell histology is the standard R-CHOP regimen. Rituximab plays an essential role in treatment of CD20-positive B-cell lymphoma (12]. Radiotherapy is used in Partial response cases [12]. Overall survival ranged from 6 months to 41 months with median OS of 23 months in our study.

2) Monterroso V, Jaffe ES, Merino MJ, Medeiros LJ. Malignant lymphomas involving the ovary. Am J Surg Pathol 1993; 17:154-70.

3) Osborne BM, Robboy SJ. Lymphomas or leukemia presenting as ovarian tumors. An analysis of 42 cases. Cancer 1983; 52:1933-43.

4) Suzuki T, Sasano H, Takaya R, Fukaya T, Yajima A, Date $\mathrm{F}$, et al. Leukocytes in normal-cycling human ovaries: immunohistochemical distribution and characterization. Hum Reprod1998;13:2186-91

5) Hussell T, Isaacson PG, Crabtree JE, Spencer J. The response of cells from low-grade B-cell gastric lymphomas of mucosaassociated lymphoid tissue to Helicobacter 
pylori. Lancet $1993 ; 4: 571-4$

6) M. A. Dimopoulos, D. Daliani, W. Pugh, D. Gershenson, F.Cabanillas, and A. H. Sarris, "Primary ovarian nonHodgkin's lymphoma: outcome after treatment with combination chemotherapy,"Gynecologic Oncology, vol. 64, no. 3, pp. 446-450, 1997.

7) V. Monterroso, E. S. Jaffe, M. J. Merino, and L. J. Medeiros, "Malignant lymphomas involving the ovary: a clinicopathologic analysis of 39 cases," American Journal of Surgical Pathology, vol.17, no. 2, pp. 154-170, 1993.

8) H. Fox, F. A. Langley, A. D. T. Govan, S. A. Hill, andM.H. Bennett,"Malignant lymphoma presenting as an ovarian tumour: a clinicopathological analysis of 34 cases," British Journal of Obstetrics and Gynaecology, vol. 95, no. 4, pp. 386-390, 1988.

9) R. Vang, L. J. Medeiros, R. A. Warnke, J. P. Higgins, and M. T.Deavers, "Ovarian non-Hodgkin's lymphoma: a clinicopathologic study of eight primary cases," Modern Pathology, vol. 14, no. 11, pp. 1093-1099, 2001.
10) A. S.Weingertner, D. Hamid, M. N. Roedlich, and J. J. Baldauf, "Non-Hodgkin malignant lymphoma revealed by an ovarian tumor: case report and review of the literature," Gynecologic Oncology, vol. 95, no. 3, pp. 750-754, 2004.

11) P. Feugier, A. Van Hoof, C. Sebban et al., "Long-term results of the R-CHOP study in the treatment of elderly patients with diffuse large B-cell lymphoma: a study by the groupe d'etude deslymphomes de l'adulte," Journal of Clinical Oncology, vol. 23, no.18, pp. 4117-4126, 2005.

12) N. Sakurai, K. Tateoka, J. Taguchi, and T. Terada, "Primary precursor B-cell lymphoblastic lymphoma of the ovary: case report and review of the literature," International Journal of Gynecological Pathology, vol. 27, no. 3, pp. 412-417, 2008.

13) M. A. Dimopoulos, D. Daliani, W. Pugh, D. Gershenson, F.Cabanillas, and A. H. Sarris, "Primary ovarian nonHodgkin'slymphoma: outcome after treatment with combination chemotherapy," Gynecologic Oncology, vol. 64, no. 3, pp. 446-450, 1997

Table 1: Showing patient characteristics, treatment and outcome

\begin{tabular}{|c|c|c|c|c|c|c|c|c|c|c|c|}
\hline $\begin{array}{l}\text { CASE } \\
\text { NO. }\end{array}$ & $\underset{\mathbf{E}}{\mathbf{A G}}$ & $\begin{array}{c}\text { CLINICA } \\
\text { L } \\
\text { FEATURE } \\
\mathbf{S} \\
\end{array}$ & $\begin{array}{l}\mathbf{P} \\
\mathbf{S}\end{array}$ & $\begin{array}{c}\text { IP } \\
\text { I }\end{array}$ & $\begin{array}{c}\text { STAG } \\
\text { E }\end{array}$ & IHC & $\begin{array}{l}\text { HISTOLOG } \\
\text { Y }\end{array}$ & $\begin{array}{l}\text { SURGER } \\
\text { Y }\end{array}$ & $\begin{array}{l}\text { CHEMOTHERA } \\
\text { PY }\end{array}$ & $\begin{array}{l}\mathbf{R} \\
\mathbf{T}\end{array}$ & OUTCOME \\
\hline 1 & 41 & $\begin{array}{c}\text { Pain } \\
\text { abdomen }\end{array}$ & 2 & 2 & IV BE & $\begin{array}{l}\text { LCA, CD20, } \\
\text { bcl2, bcl6, } \\
\text { MUM1 }\end{array}$ & DLBCL & TAH/BSO & RCHOPX 6 & $\mathrm{Y}$ & $\begin{array}{c}\text { ALIVE PR } \\
\text { OS- } 20 \\
\text { months }\end{array}$ \\
\hline 2 & 43 & $\begin{array}{l}\text { Abdominal } \\
\text { swelling }\end{array}$ & 1 & 1 & I BE & $\begin{array}{c}\text { CD 20,CD45, } \\
\text { bcl2 }+ \\
\text { CD3---- }\end{array}$ & DLBCL & TAH/BSO & CHOPX6 & - & $\begin{array}{c}\text { NED LTFU } \\
\text { OS - } 22 \\
\text { MONTHS }\end{array}$ \\
\hline 3 & 59 & $\begin{array}{l}\text { Pelvic } \\
\text { mass }\end{array}$ & 1 & 0 & $\mathrm{I} \mathrm{AE}$ & CD10, bcl6 + & DLBCL & TAH/BSO & CHOPX 6 & - & $\begin{array}{c}\text { NED LTFUP } \\
\text { Os }-41 \\
\text { months } \\
\end{array}$ \\
\hline 4 & 53 & $\begin{array}{l}\text { Abdominal } \\
\text { swelling } \\
\text { Pain } \\
\text { Abdomen } \\
\end{array}$ & 2 & 2 & IV BE & $\mathrm{CD} 20, \mathrm{bcl} 2+$ & DLBCL & TAH/BSO & CHOPX6 & - & $\begin{array}{l}\text { NED LTFU } \\
\text { OS- } 6 \text { months }\end{array}$ \\
\hline
\end{tabular}

F- female; M-male; DLBCL: diffuse large B cell lymphoma; CHOP- Cyclophosphamide, Hyroxy daunorubicin, Oncovin, Prednisone; LTFU- lost to follow up; OS- overall survival; NED: No evidence of disease; E- Extra nodal; A- absence of B symptoms; B - B symptoms present; R- CHOP: Rituximab, Cyclophosphamide, Hyroxy daunorubicin, Oncovin, Prednisone, IPI: International prognostic index, PR: Partial Response, IMVP-16 - Ifosfamide, Mesna, Etoposide. 


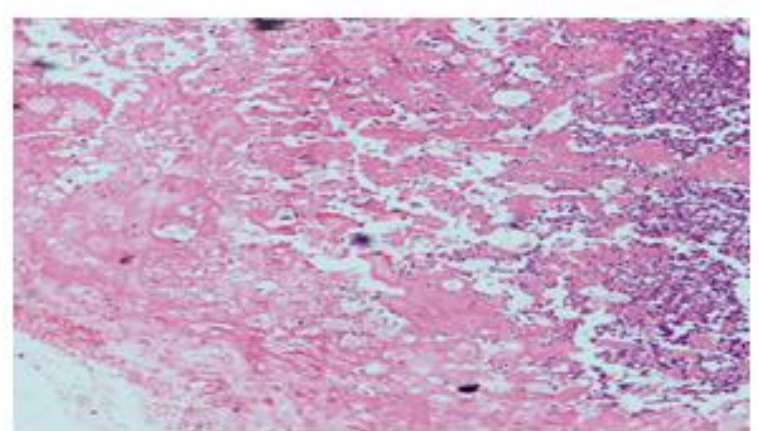

Figure 1(A) Shouks non cohesive neoplastic cells in a diffuse pattern.

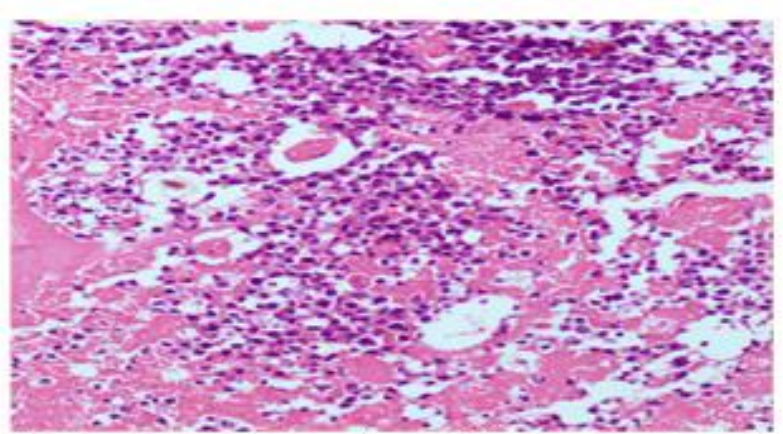

Figure 1(B). Large lymphoma cells have round nuclei and moderate amount of cytoplasm.

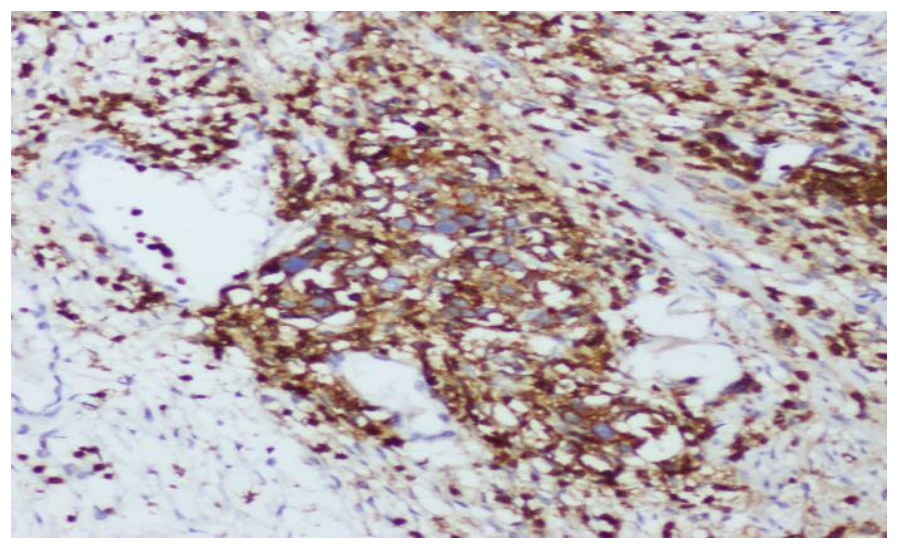

Figure 2 Shows neoplastic cells are positive for CD20 on IHC. 